\title{
The Effect of Light and Heat Upon Choroidal Thickness in Healthy Young Adults
}

\author{
Saleh A AlKhaldi ${ }^{*}$ and Lyle S Gray ${ }^{2}$ \\ ${ }^{1}$ Department of Ophthalmology, King Saud Medical City, Riyadh, Saudi Arabia \\ ${ }^{2}$ Department of Vision Sciences, Glasgow Caledonian University, Glasgow, UK \\ *Corresponding Author: Saleh A AlKhaldi, Department of Ophthalmology, King \\ Saud Medical City, Riyadh, Saudi Arabia.
}

Received: February 24, 2021

Published: March 10, 2021

(C) All rights are reserved by Saleh A AlKhaldi and Lyle S Gray.

\section{Abstract}

Aim: Investigate the effect of external factors such light and heat upon choroidal thickness in healthy adults.

Methods: 40 young healthy adults were included in this study. Choroidal thickness was measured using swept source optical coherence tomography before and after they were exposed to different levels of light illumination and external source of heat. In the first experiment, 30 subjects were divided into 3 refractive groups (myopes, emmetropes and hyperopes). In the second experiment, another 10 myopic subjects wore pre-heated eye compress for 10 minutes.

Results: In the first experiment, no significant change in choroidal thickness was recorded after exposing the subjects to 4 different illuminations and this was the case for all participants ( $p>0.05)$. In the second experiment, no significant change in choroidal thickness was found duo to wearing the eye compress for 10 minutes in all choroidal areas except for the outer nasal area ( $p>0.05$ ). However, one subject showed substantial change in all choroidal areas.

Conclusion: Short exposure to different illuminations has no significant effect upon choroidal thickness. Wearing pre-heated eye compress did not substantially affect choroidal thickness except for outer nasal area, while one subject showed substantial change in all choroidal areas which requires further investigation.

Keywords: Choroid; Choroidal Thickness; Optical Coherence Tomography; Light Exposure; Outdoor Activity; Eye Compress

\section{Introduction}

The choroid is highly vascularised structure located in the posterior half of the eye. The main function of the choroid is to supply oxygen and nutrients to the outer retina, and also to the inner retina in species with avascular retina [1,2]. The choroid has other important functions such as modulating the temperature of the eye by thermal dispersion, regulating intra ocular pressure by controlling blood flow, and the absorption of stray light in species with pigmented choroids [1,2].
There is growing evidence from animal studies to suggest that ambient light exposure may be an important environmental factor in the regulation of refractive development. Previous studies showed that chicks raised in a normal visual environment with average light intensity and a normal day/night cycle, had normal eyes development towards emmetropia and show no or minimal changes in the refractive status $[3,4]$.

Other studies show that when chicks are exposed to low intensity of light with a normal circadian cycle, they developed myopia 
$[3,5,6]$. Furthermore, when chicks were exposed to high intensity of light with a normal circadian cycle, they developed hyperopia $[4,6,7]$.

Exposure to high levels of illumination seems to prevent the progression of form deprivation myopia in rhesus monkeys [8] as well as chicks $[9,10]$. High levels of illumination appear to slow myopia progression induced by negative lenses in chicks [11]. In contrast, when myopia was induced by negative lenses in infant monkeys, high levels of illumination had no significant effect on the development of myopia [12].

A number of studies have been conducted to examine the influence of exposure to high levels of illumination on human eyes. One study examined 101 school children including 41 myopes and 60 non-myopes measuring axial length at four visits over a period of 18 months. The mean spherical equivalent (MSE) for the myopic group was $-2.39 \pm 1.50 \mathrm{D}$ and for the non-myopic group was +0.34 $\pm 0.30 \mathrm{D}$. The age of the subjects ranged between 10 and 15 years old. The daily light exposure was obtained from light sensors worn on the wrist (Actiwatch 2, Philips Respironics, Pittsburgh, PA, USA). Subjects wore the light sensor for two individual 14-day periods, separated by 6 months. The study found a statistically significant relationship between axial eye growth and average daily light exposure, with axial length increase being slower in children exposed to a higher overall illumination (1455 \pm 317-lux), whereas children who experienced lower levels of daily light exposure $(459 \pm 117$ lux) showed significant increase in axial eye growth [13].

Another study investigated sub-foveal choroidal thickness (SFCT) in 27 healthy myopic subjects aged between 19 to 29 years old (mean age $=25.85 \pm 2.20$ years). Refractive error varied from $-1.00 \mathrm{D}$ to $-5.87 \mathrm{D}$ (MSE=-3.15 $\pm 2.00 \mathrm{D}$ ). All subjects were exposed to 150-lux for 4 hours before sleep in the first 2 nights. Subsequently, subjects were exposed to 1000-lux for 4 hours before sleep, on 5 consecutive nights. The results revealed a significant reduction in SFCT from $268 \pm 57.10 \mu \mathrm{m}$ in the first 2 nights to $245.00 \pm 52.84 \mu \mathrm{m}$ $(p<0.05)$ after subjects were exposed to the 1000 lux intensity for the subsequent five nights showing that choroidal thickness (CT) can be altered by exposure to bright light in the evening time [14].

Alagoz., et al. (2016) evaluated the alterations of SFCT during dark and light adaptation in twenty four healthy adults aged between 22 and 42 years old (mean age=30.4 \pm 4 .4years). MSE re- fraction ranged from $-1.00 \mathrm{D}$ to $+1.00 \mathrm{D}$. SFCT was measured 3 times between $16: 30 \mathrm{pm}$ and $17: 30 \mathrm{pm}$. The first reading represented a baseline, and the second reading was obtained after 30 minutes of dark adaptation $\left(0.0 \mathrm{~cd} / \mathrm{m}^{2}\right)$, while the third reading was obtained after 5 minutes of light adaptation $\left(80 \mathrm{~cd} / \mathrm{m}^{2}\right)$. A significant increase $(\mathrm{p}<0.05)$ in SFCT was found after dark adaption with the post adaptation thickness being $392.10 \pm 100.90 \mu \mathrm{m}$ compared to the baseline of $369.90 \pm 93.30 \mu \mathrm{m}$, indicating that CT becomes thicker in the dark. Furthermore, SFCT returned to baseline values after light adaptation [15].

Based on the argument that exposure to high levels of daylight may prevent myopia, Hagen., et al. (2018) examined the prevalence of myopia in 393 Norwegian Caucasian subjects aged from 16 to 19 year old in Norway ( $60^{\circ}$ latitude North), where people are experiencing low levels of daylight in autumn and winter. They reported that the overall prevalence of myopia $(\leq-0.50 \mathrm{D})$ was $13 \%$, which is way lower than in East Asian Countries [16].

Few reports in the literature can be found regarding the effect of exposure to different levels of illumination on CT in human subjects. In addition, a literature search identified no previous work investigating the effect of heat applied externally upon the choroid.

The aim of the current study is to investigate the effect of external factors such light and heat upon choroidal thickness (CT) in healthy adults.

\section{Experiment 1}

Methods

Thirty young, healthy adults (10 myopic, 10 emmetropic, and 10 hyperopic) were recruited from the student population at Glasgow Caledonian University. The age of the participants ranged between 18 and 28 years old (mean $\pm \mathrm{SD}=21.70 \pm 2.29$ years). Refraction in the myopic group ranged between $-2.00 \mathrm{D}$ and $-5.00 \mathrm{D}$ (MSE $\pm \mathrm{SD}=-$ $3.08 \pm 1.00 \mathrm{D}$ ) and the mean age was $22.70 \pm 3$.46years. Refraction in the emmetropic group ranged between 0.00D and +0.50D (MSE $\pm \mathrm{SD}=0.12 \pm 0.29 \mathrm{D}$ ) and the mean age was $21.30 \pm 0.67$ years. In the hyperopic group, refraction ranged between +2.00D and +9.00D (MSE $\pm \mathrm{SD}=3.50 \pm 2.33 \mathrm{D}$ ) with a mean age of $21.10 \pm 1.66$ years (see Table 7-1 for more details). Subjects with any ocular or systemic pathology, or astigmatism less than $-1.25 \mathrm{DC}$ were excluded. All participants had best corrected visual acuity of $6 / 6$ or better in both eyes. 
The experiment was approved by the School of Health and Life Sciences Ethics Committee at Glasgow Caledonian University and was conducted in accordance with the Declaration of Helsinki for research involving human subjects. All participants completed a consent form and were given information leaflets, after verbal explanation about the nature of the study and any possible consequences.

Instrumentation

Topcon SS OCT

CT was measured using Swept Source Optical Coherence Tomography (SS OCT). The SS OCT (Topcon Inc, Tokyo, Japan) is a new generation of high penetration OCT devices which use a tunable laser to allow visualisation of ocular layers below the retina [17-19].

\section{Source of illumination}

A Kodak Slide Projector (EKTAPRO 5000, Stuttgart, Germany) was used to present varying levels of illumination to the subjects. This projector is equipped with internal halogen bulb (300W), and neutral density (ND) filters were used to change the level of illumination. Four ND filters were used to obtain illuminance levels of: $1 \mathrm{~cd} / \mathrm{m}^{2}, 50 \mathrm{~cd} / \mathrm{m}^{2}, 300 \mathrm{~cd} / \mathrm{m}^{2}$, and $1000 \mathrm{~cd} / \mathrm{m}^{2}$. The intensity of light for each filter was measured using Minolta Chroma Meter CS-100 (Minolta Camera Co, LTD, Japan) placed on tripod at the eye position of the subjects.

\section{Presentation of illumination}

The experiment was conducted in a small dark room $(2 \times 2 \mathrm{~m})$. An opaque plastic diffuser panel $(17.50 \times 17.50 \mathrm{~cm})$ attached to a wooden box (15cm depth) was placed in front of the projector and the subject viewed this evenly illuminated panel through the open end of the box. All subjects were exposed to the dimmest illumination first and then the illumination levels were increased in order. Exposure time for each illumination was ten minutes and subjects were prohibited from using any other source of light or to close their eyes during the experiment, but they were able to blink normally.

\section{Measurement of CT}

All subjects were examined at the same time of day, between $12: 00 \mathrm{pm}$ and 2:00pm, and one subject was examined per day. At the beginning of the experiment, baseline measurements of SFCT were acquired for each participant by the SS OCT applying fundus guided acquisition mode (FGA), a special feature allows examining the same area again. Subjects were then exposed to each illumination as described above. Following exposure to each illumination level, four measurements of SFCT were acquired per subject.

\section{Data analysis}

SPSS software version 22 for Windows (SPSS Inc., Chicago, IL, USA) was used to perform statistical analysis for our data (www. ibm.com/software/analytics/spss/). A Shapiro-Wilk test was performed to determine the normality. Since the data is normally distributed (parametric), repeated measures ANOVA test was used to analyze the short-term changes in CT between the different experimental conditions. Results were considered statistically significant if the $\mathrm{p}$ value is $<0.05$.

\section{Results}

SFCT at baseline ranged from $138 \mu \mathrm{m}$ to $432 \mu \mathrm{m}$ (mean \pm $\mathrm{SD}=273.30 \pm 75.20 \mu \mathrm{m}$ ) for the myopic group, $241 \mu \mathrm{m}$ to $509 \mu \mathrm{m}$ for the emmetropic group (mean $\pm \mathrm{SD}=362.20 \pm 99.09 \mu \mathrm{m}$ ), and $236 \mu \mathrm{m}$ to $515 \mu \mathrm{m}$ (mean $\pm \mathrm{SD}=359.10 \pm 98.12 \mu \mathrm{m}$ ) for the hyperopic group. Myopic subjects had thinner choroid than emmetropic and hyperopic subjects as expected (see table 1).

\begin{tabular}{|l|c|c|c|}
\hline Refractive group & Myopic & Emmetropic & Hyperopic \\
\hline $\begin{array}{l}\text { Number of } \\
\text { subjects }\end{array}$ & 10 & 10 & 10 \\
\hline Age rang (years) & 18 to 28 & 18 to 28 & 18 to 28 \\
\hline Age mean (years) & $\begin{array}{c}22.70 \pm \\
3.46\end{array}$ & $21.30 \pm 0.67$ & $\begin{array}{c}21.10 \pm \\
1.66\end{array}$ \\
\hline Refractive range & $\begin{array}{c}-2.00 \text { to } \\
\text { (D) }\end{array}$ & plano to +0.50 & $\begin{array}{c}+2.00 \text { to } \\
+9.00\end{array}$ \\
\hline MSE (D) & $\begin{array}{c}-3.08 \pm \\
-1.00\end{array}$ & $0.12 \pm 0.29$ & $3.50 \pm 2.33$ \\
\hline SFCT range $(\mu \mathrm{m})$ & $\begin{array}{c}138 \text { to } \\
432\end{array}$ & 241 to 509 & 236 to 515 \\
\hline SFCT mean $(\mu \mathrm{m})$ & $\begin{array}{c}273.30 \pm \\
75.20\end{array}$ & $362.20 \pm$ & $359.10 \pm$ \\
99.09 & 98.12 \\
\hline
\end{tabular}

Table 1: Shows summary of the key information for all groups. Values show mean \pm SD.

In all groups, no systematic change in SFCT was identified from short-term light exposure to different illuminations (Figure 1, 2 and 3). Moreover, there was no significant variation in CT with changes in luminance exposure $(\mathrm{P}>0.05)$. 


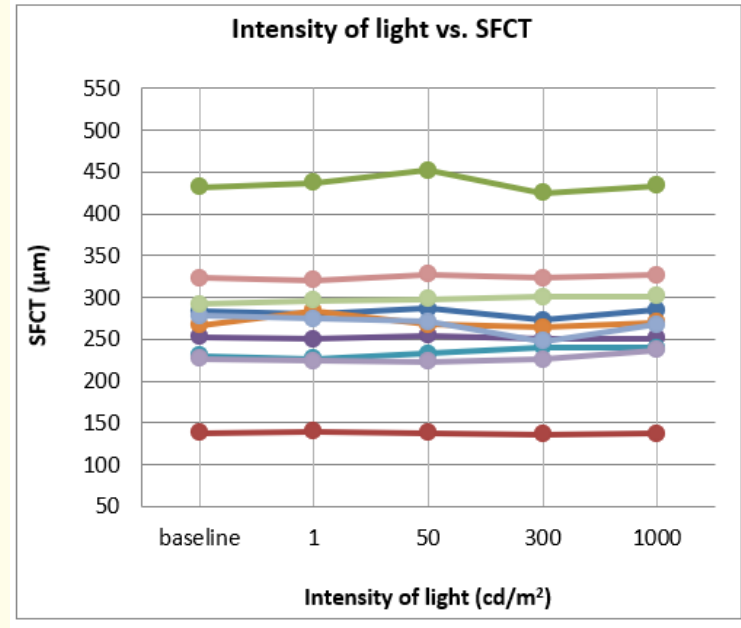

Figure 1: Shows the change in SFCT of each subject in the myopic group following exposure to the different levels of illumination.

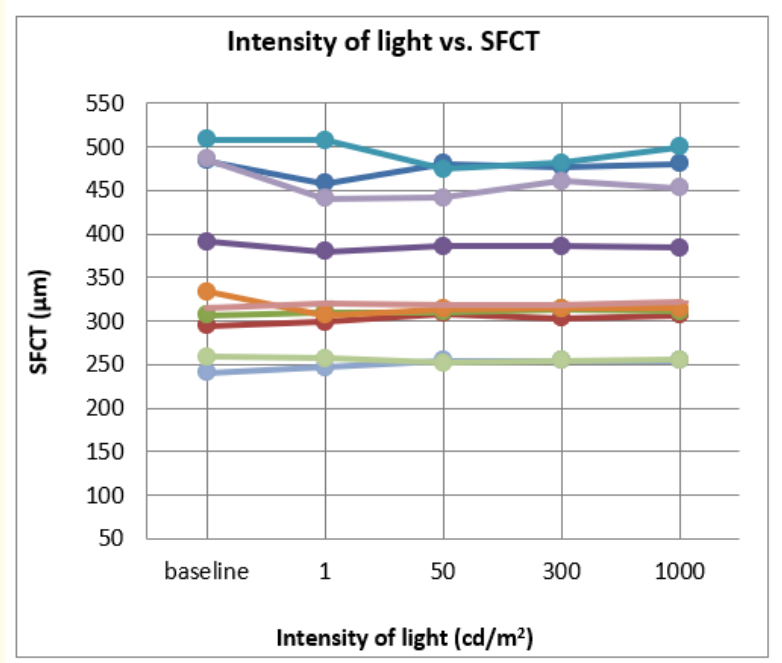

Figure 2: Shows the change in SFCT of each subject in the emmetropic group following exposure to the different levels of illumination.

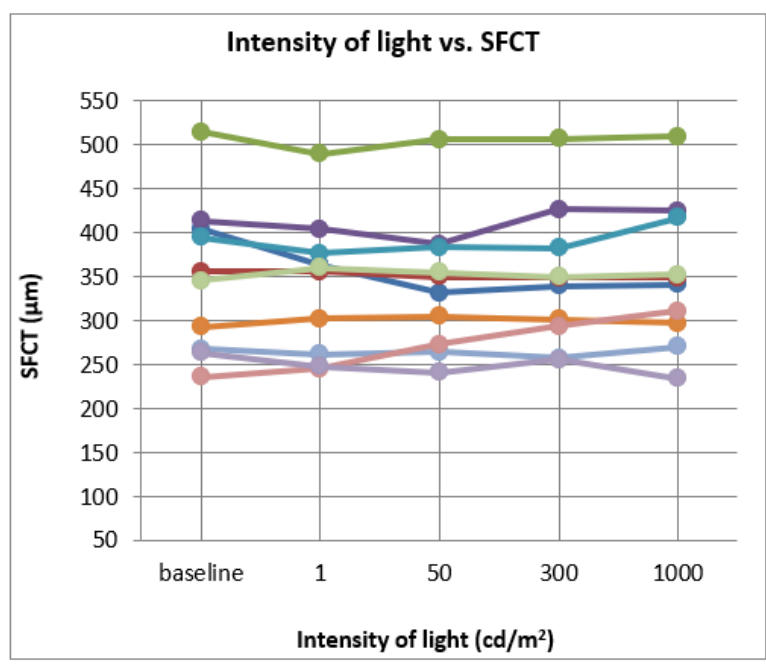

Figure 3: Shows the change in SFCT of each subject in the hyperopic group following exposure to the different levels of illumination.

\section{Experiment 2}

Methods

Ten healthy myopic adults ( 4 males and 6 females) were recruited from the student population at Glasgow Caledonian University. The age of the participants ranged between 18 and 28 years old (mean $\pm \mathrm{SD}=22 \pm 3.68$ years). The group refraction ranged between $-1.50 \mathrm{D}$ and $-5.00 \mathrm{D}$ (mean $\pm \mathrm{SD}=-2.95 \pm 1.10 \mathrm{D})$ with astigmatism of no less than -1.25DC. Subjects who had previous or current ocular pathology, ocular surgery or chronic systemic disease (e.g. diabetes) were excluded. All participants included in the study had best corrected visual acuity of $6 / 6$ or better in both eyes. Nine subjects were Caucasian and one was Hispanic.

The experiment was approved by the School of Health and Life Sciences Ethics Committee and was conducted in accordance with the Declaration of Helsinki for research involving human subjects. All participants completed a consent form and were given information leaflets, after verbal explanation about the nature of the study and any possible consequences. 


\section{Instrumentation}

Topcon SS OCT

See experiment 1 for more details.

\section{Eye compress}

A Bruder MediBeads eye compress (Bruder Health Care Company, Atlanta, USA) was used to apply heat to the eye (Figure 4). This heated compress is recommended in practice to alleviate symptoms of dry eye, Meibomian Gland Dysfunction, and blepharitis. The microbeads within the compress are activated to produce heat by microwave radiation at $800 \mathrm{~W}$ output power for a duration of 20 seconds. The Bruder eye mask may reach a temperature as high as of approximately $52^{\circ} \mathrm{C}$ for the first minute after heating and maintains a temperature $\sim 50^{\circ} \mathrm{C}$ for the first 5 minutes, before slowly cooling [20]. Where the mask feels too hot for the subject, the manufacturers recommend that it should be removed and re-applied one or two minutes later. In addition, the manufacturers state that after removal, subjects might experience blurred vision due to released meibum. Generally, vision returns to normal in a short time [21]. The Bruder eye mask must be tested on patient's eye before fully applying it in order to prevent eyelid burns [22].

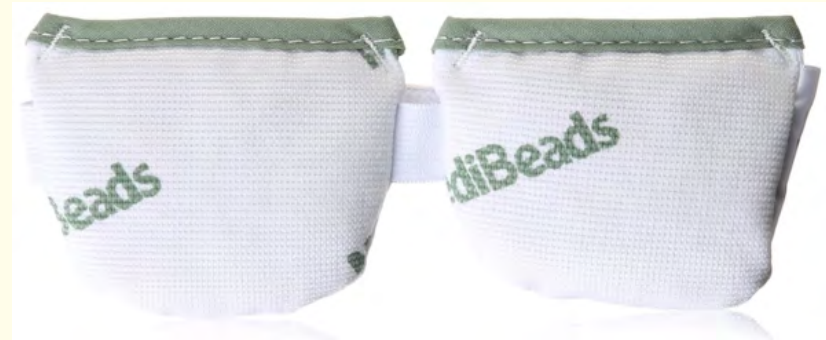

Figure 4: Shows the re-usable Medibeads eye compress which can be heated by microwave. The image was taken from Bruder Health Care official website.

\section{Measurements of CT}

All subjects were examined between 12:00pm and 2:00pm in the Vision Centre of the University in order to avoid confounding factors such as diurnal variation of CT. At the beginning of the experiment, a baseline measurement of CT for the right eye was acquired using the SS OCT (FGA mode). The subject then wore the eye compress for 10 minutes after it was pre-heated as described. A second scan was then obtained immediately upon removal of the eye compress. The temperature of the eye compress was measured directly after heating and at the end of the 10-minute wear period. In addition, eyelid temperature was measured before and after wearing the eye compress. These areas are: cen-tral foveal area (1 $\mathrm{mm}$ diameter), inner circle ( $3 \mathrm{~mm}$ diameter) and outer circle (6 $\mathrm{mm}$ diameter), which are divided into four quad-rants: superior, nasal, inferior and temporal). The central area of $1 \mathrm{~mm}$ is defined as the subfoveal choroidal thickness (SFCT) while the 3 $\mathrm{mm}$ inner circle and $6 \mathrm{~mm}$ outer circle represent the parafo-veal and perifoveal regions respectively [19]. The temperature was measure using in-frared thermometer THI-700 (Tasco, Japan).

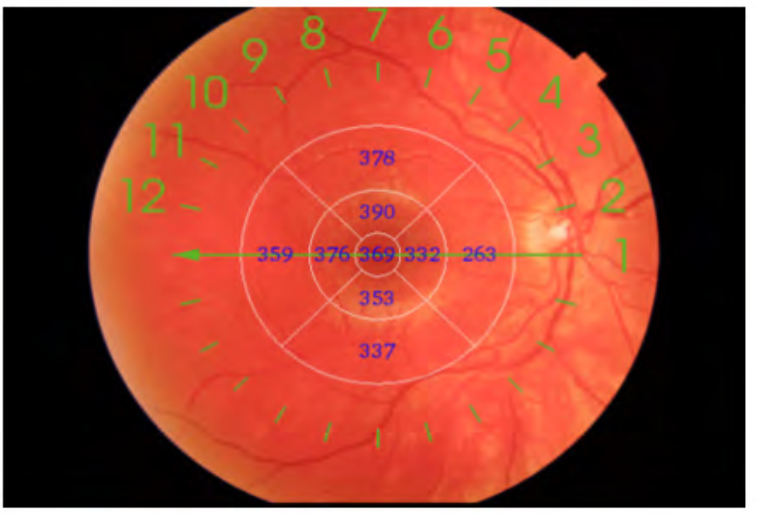

Figure 5: Shows the map of nine choroidal thickness areas based on the ETDRS grid.

\section{Data analysis}

SPSS software version 22 for Windows (SPSS Inc., Chicago, IL, USA) was used to perform statistical analysis for our data (www. ibm.com/software/analytics/spss/).

A Shapiro-Wilk test was performed to determine the normality. Since the data is normally distributed (parametric), paired samples t-test was used to analyze the short-term changes in CT before and after wearing the eye mask. Results were considered statistically significant if the $\mathrm{p}$ value is $<0.05$.

\section{Results}

The SFCT in the subject group ranged from $218 \mu \mathrm{m}$ to $335 \mu \mathrm{m}$ (mean $\pm \mathrm{SD}=267 \pm 34.34 \mu \mathrm{m}$ ). Table 2 displays the summary of CT measurements $(\mu \mathrm{m})$ according to ETDRS grid, before and after wearing the preheated eye compress for ten minutes. Values show mean \pm SD. 


\begin{tabular}{|l|c|c|c|}
\hline $\begin{array}{c}\text { Choroidal area } \\
\text { (ETDRS) }\end{array}$ & Pre heated & Post heated & $\begin{array}{c}\text { P } \\
\text { value }\end{array}$ \\
\hline $1 \mathrm{~mm}$ central & $277.00 \pm 47.63$ & $279.80 \pm 48.64$ & $>0.05$ \\
\hline $3 \mathrm{~mm}$ superior & $293.10 \pm 37.52$ & $295.40 \pm 39.17$ & $>0.05$ \\
\hline $3 \mathrm{~mm}$ nasal & $242.60 \pm 43.84$ & $249.40 \pm 42.75$ & $>0.05$ \\
\hline $3 \mathrm{~mm}$ inferior & $265.40 \pm 55.64$ & $267.20 \pm 55.25$ & $>0.05$ \\
\hline $3 \mathrm{~mm}$ temporal & $283.80 \pm 43.02$ & $286.80 \pm 48.84$ & $>0.05$ \\
\hline $6 \mathrm{~mm}$ superior & $279.00 \pm 29.83$ & $282.20 \pm 30.03$ & $>0.05$ \\
\hline $6 \mathrm{~mm}$ nasal & $179.10 \pm 36.09$ & $185.80 \pm 35.79$ & $<0.05^{*}$ \\
\hline $6 \mathrm{~mm}$ inferior & $243.00 \pm 62.43$ & $242.50 \pm 59.69$ & $>0.05$ \\
\hline $6 \mathrm{~mm}$ temporal & $271.30 \pm 39.96$ & $276.00 \pm 47.95$ & $>0.05$ \\
\hline
\end{tabular}

Table 2: Shows summary of CT measurements in all choroidal areas before and after wearing the pre-heated eye compress.

No significant variation in CT was found as a result of applying heat to the eye and this was the case for 8 ETDRS areas of the choroid ( $p>0.05)$, except for the outer nasal area $(p<0.05)$. It is worth noting however that while the overall change is not significant, every ETDRS area showed an increase in the group mean CT (Figure 6).

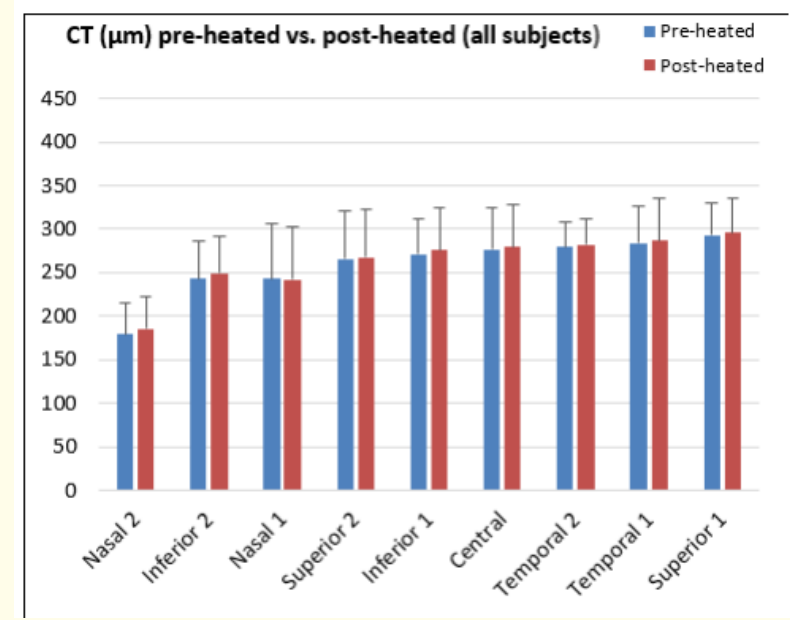

Figure 6: Demonstrates the measurements of CT (all subjects) in all 9 choroidal areas (ETDRS) before and after wearing the preheated eye mask for 10 minutes. Error bars represent SD.

One subject (Hispanic) showed substantial post-heating increases in CT for all areas due to an increase in external ocular temperature, and these results can be seen in figure 7 . This subject was a girl, 27 years old, and her prescription for the right eye was $-3.75 \mathrm{DS}$.

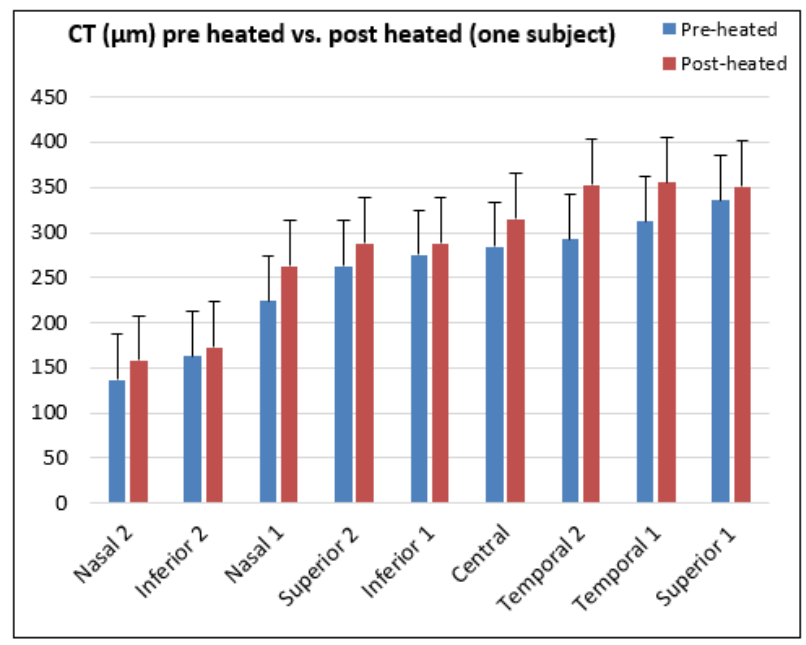

Figure 7: Shows how the CT measurements for one subject changed significantly in all 9 ETDRS areas as a result of wearing the pre-heated eye mask for 10 minutes. The data shows an increase in all CT areas. Error bars represent SD.

The eye compress temperature after activation but before wearing ranged between $49^{\circ} \mathrm{C}$ and $54^{\circ} \mathrm{C}$ (mean $\pm S D=52.07 \pm 2.14$ ), and after wearing ranged between $34^{\circ} \mathrm{C}$ and $36.50^{\circ} \mathrm{C}$ (mean $\pm \mathrm{SD}=34.50$ $\pm 0.73^{\circ}$ ). The eyelid temperature prior to application of the compress ranged between $33^{\circ} \mathrm{C}$ and $35^{\circ} \mathrm{C}\left(\right.$ mean $\left.\pm \mathrm{SD}=33.68 \pm 0.63^{\circ}\right)$, and upon removal of the compress ranged between $34.50^{\circ} \mathrm{C}$ and $36.50^{\circ} \mathrm{C}\left(\right.$ mean $\pm \mathrm{SD}=35.28 \pm 0.63^{\circ}$ ) (Figure 8).

\section{Discussion}

This study evaluates the effect of external factors such light and heat upon CT in healthy adults. The results of the first experiment show that short-term exposure to different levels of illumination has no significant effect on CT in any of the subject groups.

Previous report shows a statistically significant relationship between slower axial eye growth and daily exposure to ambient light 


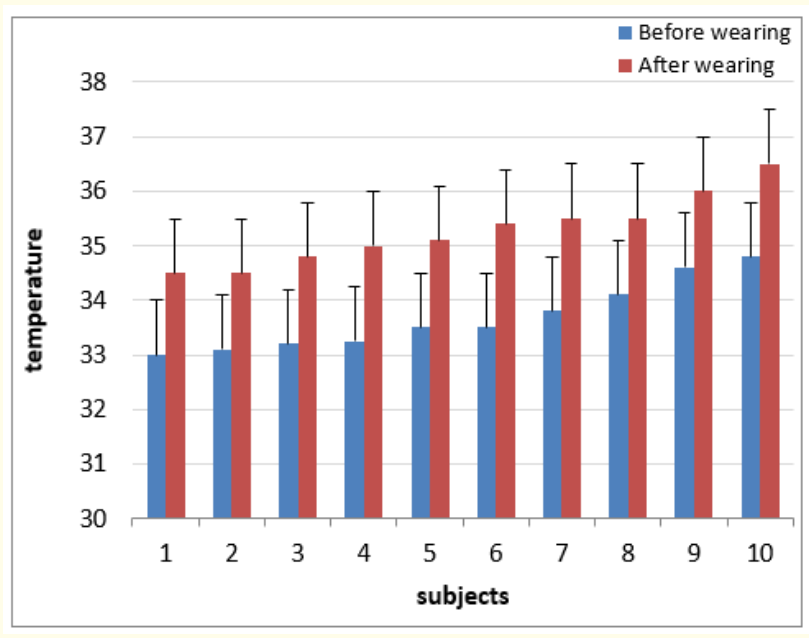

Figure 8: Shows eyelid temperature (Celsius) before and after wearing the pre heated eye mask for 10 minutes. Error bars represent SD.

in school children [13]. Earlier studies also reported a link between daytime outdoor activities and associated bright light exposure with a reduced prevalence of myopia and reductions in the rate of myopic progression in school children $[23,24]$.

Increased daily exposure to high intensity light more than 3000- lux (light levels which are typically encountered outdoors) was significantly related to reduced axial eye growth $(\mathrm{p}<0.05)$ in myopic and non-myopic children. On the other hand, a significant association $(\mathrm{p}<0.05)$ was also found between daily exposure to low illumination (459 \pm 117-lux) and faster axial eye growth in children. In addition, lower time involved in outdoor activities $(<40$ minute per day) was associated with faster axial eye growth when comparing with 70 minutes of outdoor activities per day [13].

A number of previous reports examining the relationship between myopia progression and outdoor activity in school children lack consensus. A randomized clinical trial on myopic children (3 years period) found that extended outdoor activities were associated significantly with less myopia development [25].

Another study (12 months period) conducted on myopic and non-myopic Chinese school children (derived from questionnaire data) found a significant relationship between less axial eye growth and greater outdoor time [24]. On the other hand, a large population study, conducted by questionnaire, found that time spent on sports and outdoor activities had no significant effect on myopic progression [26]. Furthermore, short exposure to darkness (when going to sleep) might contribute to increased rates of myopic progression among young university students [27].

Several studies have documented significant seasonal variations of axial eye growth in myopic children, with increased rate of eye growth due to more light exposure during summer than in winter [28-31].

In the current study, while the range of illuminations used was quite varied and included both very bright and dim light levels, it may be that the duration of exposure is an important factor in whether illumination level affects choroidal/retinal physiology. Previous work has suggested that the rate of myopia progression can be modulated by very bright light exposure (above 3000-lux), and if this effect is produced via alterations in choroidal physiology similar to those found in animal models then some effect of illumination upon CT might be expected. In our experiment, subjects were exposed to each illumination level for ten minutes. Possibly, this was not a sufficient exposure duration to affect the choroid.

A recent paper found that CT increased significantly in response to dark adaptation. Compared to the present study, they measured CT in the evening (between 16:30pm and 17:30pm), also the exposure time, i.e. time of dark adaptation was longer (30 minutes) [15]. Another recent study found reductions in SFCT following exposure to a high intensity of light for several days just before sleep. Again, the measurements were conducted at night and the exposure duration was longer than the current study [14].

These differences may explain the variations in results between the current study and the previous studies. However, Additional research with larger sample size as well as longer time of light exposure may be appropriate to obtain greater insights in terms of examining the effect of both darkness and bright light on the choroid and other ocular parameters.

The results of the second experiment show that the application of external heat to the eye produced no significant effect on CT in this myopic subject group, except for the outer nasal area. It is not 
clear at this point why there is a significant change in this region and further work is required. In addition, one subject (Spanish) shows a clear increase in CT for all the nine choroidal areas after wearing the eye compress. It is notable that while there was no significant group change, there was a tendency for the CT to increase after the application of heat, although the changes tended to be small.

Although there was no similar published work could be found in the literature so that we can compare our results to previous research, the finding that external heat produced a substantial effect on CT in one subject suggest that extending the work to a larger group of subjects and changing the experimental paradigm would be worthwhile.

\section{Conclusion}

The findings of the current study suggest that short-term exposure to different illuminations of light has no significant effect on SFCT. In addition, no significant group effect of external heat upon $\mathrm{CT}$, except for the outer nasal region. Currently, it is not clear whether applying heat on the human eye has an influence on CT since our study is the first to investigate this relationship. Investigating changes in the choroid in response to external factors such as daily light exposure should be considered to enhance our understanding of choroidal role in modulation of refractive error progression.

\section{Bibliography}

1. Nickla DL and Wallman J. "The multifunctional choroid". Progress in Retinal and Eye Research (2010).

2. Mrejen S and Spaide RF. "Optical coherence tomography: Imaging of the choroid and beyond". Survey of Ophthalmology 58.5 (2013): 387-429.

3. Feldkaemper M., et al. "Interactions of spatial and luminance information in the retina of chickens during myopia development”. Experimental Eye Research (1999).

4. Li T., et al. "Diurnal illumination patterns affect the development of the chick eye". Vision Research (2000).

5. Norton TT., et al. "Darkness causes myopia in visually experienced tree shrews". Investigative Ophthalmology and Visual Science 47.11 (2006): 4700-4707.
6. Cohen Y., et al. "Dependency between light intensity and refractive development under light-dark cycles". Experimental Eye Research 92.1 (2011): 40-46.

7. Lauber JK. "Light-Induced Avain Glaucoma as an Animal Model for Human Primary Glaucoma". Journal of Ocular Pharmacology and Therapeutics 3.1 (1987): 77-100.

8. Smith EL., et al. "Protective effects of high ambient lighting on the development of form-deprivation myopia in rhesus monkeys". Investigative Ophthalmology and Visual Science 53.1 (2012): 421-428.

9. Ashby R., et al. "The effect of ambient illuminance on the development of deprivation myopia in chicks". Investigative Ophthalmology and Visual Science 50 (2009): 5348-5354.

10. Backhouse S., et al. "Influence of periodic vs continuous daily bright light exposure on development of experimental myopia in the chick'. Ophthalmic and Physiological Optics 33.5 (2013): 563-572.

11. Ashby RS., et al. "The effect of bright light on lens compensation in Chicks". Investigative Ophthalmology and Visual Science 51 (2010): 5247-5253.

12. Smith EL., et al. "Negative lens-induced myopia in infant monkeys: Effects of high ambient lighting". Investigative Ophthalmology and Visual Science 54.4 (2013): 2959-2969.

13. Read SA., et al. "Light exposure and eye growth in childhood". Investigative Ophthalmology and Visual Science (2015).

14. Ahn J., et al. "Effects of a high level of illumination before sleep at night on chorioretinal thickness and ocular biometry". Experimental Eye Research 164 (2017): 157-167.

15. Alagöz C., et al. "Choroidal Thickness, Photoreceptor Thickness, and Retinal Vascular Caliber Alterations in Dark Adaptation". Current Eye Research 41.12 (2016): 1608-1613.

16. Hagen LA., et al. "Prevalence and Possible Factors of Myopia in Norwegian Adolescents". Scientific Report (2018).

17. Copete S., et al. "Direct comparison of spectral-domain and swept-source OCT in the measurement of choroidal thickness in normal eyes". British Journal of Ophthalmology 9.8 (2014). 
18. Mansouri K., et al. "Evaluation of retinal and choroidal thickness by swept-source optical coherence tomography: Repeatability and assessment of artifacts". American Journal of Ophthalmology 157.5 (2014): 1022-1032.

19. Jin P., et al. "Choroidal and Retinal Thickness in Children with Different Refractive Status Measured by Swept-Source Optical Coherence Tomography". American Journal of Ophthalmology 168 (2016): 164-176.

20. Lacroix Z., et al. "Ex vivo heat retention of different eyelid warming masks". Contact Lens Anterior Eye 38.3 (2015): 152156.

21. Bitton E., et al. "In-vivo heat retention comparison of eyelid warming masks". Contact Lens Anterior Eye 39.4 (2016): 311315.

22. Alden NE., et al. "Contact burns: Is further prevention necessary?" Journal of Burn Care and Research 27.4 (2006): 472475.

23. Rose KA., et al. "Outdoor Activity Reduces the Prevalence of Myopia in Children”. Ophthalmology 115.8 (2008): 1279-1285.

24. Guo Y., et al. "Outdoor activity and myopia among primary students in rural and urban regions of Beijing". Ophthalmology 120.2 (2013): 277-283.

25. Parssinen 0 and Lyyra AL. "Myopia and myopic progression among schoolchildren: A three-year follow- up study". Investigative Ophthalmology and Visual Science 4.9 (1993): 27942802.

26. Jones-Jordan LA., et al. "Time outdoors, visual activity, and myopia progression in juvenile-onset myopes". Investigative Ophthalmology and Visual Science 53.11 (2012): 7169-75.

27. Loman J., et al. "Darkness and near work: Myopia and its progression in third-year law students". Ophthalmology 109.5 (2002): 1032-1038.

28. Fulk GW., et al. "Seasonal variation in myopia progression and ocular elongation". Optometry and Vision Science 79 (2002): 46-51.

29. Donovan L., et al. "Myopia progression in Chinese children is slower in summer than in winter". Optometry and Vision Sci- ence 89.8 (2012): 1196-202.

30. Cui D., et al. "Effect of day length on eye growth, myopia progression, and change of corneal power in myopic children". Ophthalmology (2013).

31. Gwiazda J., et al. "Seasonal variations in the progression of myopia in children enrolled in the correction of myopia evaluation trial". Investigative Ophthalmology and Visual Science 55.2 (2014): 752-758.

\section{Assets from publication with us}

- Prompt Acknowledgement after receiving the article

- Thorough Double blinded peer review

- Rapid Publication

- Issue of Publication Certificate

- High visibility of your Published work

Website: www.actascientific.com/

Submit Article: www.actascientific.com/submission.php Email us: editor@actascientific.com

Contact us: +919182824667 